\title{
O Projeto Político Pedagógico numa perspectiva coletiva
}

The Political Pedagogical Project in a collective perspective El Proyecto Político Pedagógico en una perspectiva colectiva

Recebido: 26/08/2020 | Revisado: 02/09/2020 |Aceito: 18/09/2020 | Publicado: 20/09/2020

\section{Adriana Goncalves de Sales Costa}

ORCID: https://orcid.org/0000-0002-0452-9257 Instituto Federal de Educação, Ciência e Tecnologia do Ceará, Brasil E-mail: adriana.sales@ifce.edu.br Alisandra Cavalcante Fernandes de Almeida ORCID: https://orcid.org/0000-0002-7066-1504 Instituto Federal de Educação, Ciência e Tecnologia do Ceará, Brasil E-mail: alisandra.cavalcante@ifce.edu.br

\section{Resumo}

Este artigo apresenta resultados de um estudo sobre processo de construção do Projeto Político-Pedagógico (PPP) realizado numa escola em Quixadá/Ce. Esse documento indica um caminho a ser seguido de forma explícita por uma escola. Objetivou-se investigar como ocorre a elaboração dessa política educacional, o PPP, diante do contexto educacional brasileiro que se lança nos últimos anos e qual sua conexão com a realidade escolar examinada. A metodologia adotada foi um estudo de caso, com fontes essenciais norteada pela pesquisa qualitativa na análise dos dados, foram utilizados como instrumento o questionário estruturado e o grupo focal, articulados com o quadro teórico disponível sobre o tema. Nessa pesquisa, dialogou-se com Ilma Passos Alencastro Veiga, principal teórico no aprofundamento da temática. Os resultados da investigação anunciam que o PPP tem conexão com a unidade escolar, mas para que seja efetivamente elaborado e/ou executado, com a participação integral da comunidade educativa, operando de forma democrática com o envolvimento dos diversos segmentos, de forma que venha contribuir para o trabalho pedagógico da unidade de ensino.

Palavras-chave: Política educacional; Projeto político-pedagógico; Participação; Escola; Pesquisa qualitativa. 


\section{Abstract}

This article presents the results of a study on the construction process of the PoliticalPedagogical Project (PPP) carried out at a school in Quixadá / Ce. This document indicates a path to be followed explicitly by a school. The objective was to investigate how the development of this educational policy, the PPP, takes place, given the Brazilian educational context that has been launched in recent years and what is its connection with the school reality examined. The adopted methodology was a case study, with essential sources guided by the qualitative research in the analysis of the data, the structured questionnaire and the focus group were used as instrument, articulated with the available theoretical framework on the theme. In this research, we spoke with Ilma Passos Alencastro Veiga, the main theorist in deepening the theme. The results of the investigation announce that the PPP is connected to the school unit, but for it to be effectively elaborated and / or executed, with the full participation of the educational community, operating in a democratic manner with the involvement of the various segments, in a way that it will contribute for the pedagogical work of the teaching unit.

Keywords: Educational policy; Political-pedagogical project; Participation; School; Qualitative research.

\section{Resumen}

Este artículo presenta los resultados de un estudio sobre el proceso de construcción del Proyecto Político-Pedagógico (PPP) realizado en una escuela de Quixadá / Ce. Este documento indica un camino a seguir explícitamente por una escuela. El objetivo fue investigar cómo se desarrolla el desarrollo de esta política educativa, el PPP, dado el contexto educativo brasileño que se ha lanzado en los últimos años y cuál es su conexión con la realidad escolar examinada. La metodología adoptada fue un estudio de caso, con fuentes esenciales guiadas por la investigación cualitativa en el análisis de los datos, se utilizó como instrumento el cuestionario estructurado y el grupo focal, articulado con el marco teórico disponible sobre el tema. En esta investigación, conversamos con Ilma Passos Alencastro Veiga, la principal teórica en la profundización del tema. Los resultados de la investigación anuncian que el PPP está conectado a la unidad escolar, pero para que sea efectivamente elaborado y / o ejecutado, con la plena participación de la comunidad educativa, operando de manera democrática con la participación de los distintos segmentos, de manera que contribuya para el trabajo pedagógico de la unidad didáctica. 
Palabras clave: Política educativa; Proyecto político-pedagógico; Participación; Colegio; Investigación cualitativa

\section{Introdução}

Este trabalho aborda numa perspectiva histórica, a importância da elaboração coletivamente do Projeto Político Pedagógico como tema de política educacional. Tomando como menção o contexto educacional a partir da promulgação da lei 9.394/1996 de Diretrizes e Bases da Educação Nacional (LDB) no que confere em seu artigo 12, "os estabelecimentos de ensino deveriam assumir a incumbência de elaborar e executar suas propostas pedagógicas respeitando as bases legais comuns do sistema de ensino nacional".

Anterior a essa lei, os propostas pedagógicas das unidades de ensino eram préestabelecidos por órgãos superiores da Educação, ou seja, por Secretarias Estaduais e Municipais de Educação, as unidades escolares seguiam essas orientações, aplicando esses programas sem ter a autonomia para elaborar os seus próprios planos de acordo com sua realidade local, cultural e educacional.

Dessa forma objetivou-se com esse trabalho frente a sua importância para educação avaliar o processo de elaboração do projeto político pedagógico de uma escola da rede estadual de ensino da cidade de Quixadá localizada na região do sertão central do Ceará e sua conexão com essa realidade educacional.

A LDB (9394/96) estabelece a necessidade da escola elaborar, desenvolver e avaliar seu PPP, sendo primordial a mobilização de espaços coletivos para uma discussão que envolva a elaboração desse documento, já que é uma obrigação legal às escolas, contudo, Veiga (1998) cita que “[...] a legitimidade de um projeto político-pedagógico está devidamente ligada ao grau e ao tipo de participação de todos os envolvidos com o processo educativo da escola, o que requer continuidade de ações"(p.14), assim, não deve ser construído apenas para atender à legislação nacional, mas para permitir uma análise mais apurada das realidades escolares e suas propostas pedagógicas.

A legitimidade do PPP não é totalmente consumada no ambiente escolar, pois existem barreiras que dificultam sua execução, sobretudo no tocante à sua implantação na escola. Para obter uma compreensão do PPP como um instrumento de organização e monitoramento do trabalho pedagógico da escola, procurou-se verificar se o plano está atendia à realidade escolar com base no que foi planejado. Assim, fomos motivados a realizar este estudo e formular uma pergunta que se tornou o problema de pesquisa: O PPP executado na Rede 
Estadual de Ensino do Ceará está em conexão com a realidade escolar das instituições de ensino, segundo os gestores, professores, enfim de toda a comunidade educativa?

Com o intenção de obter dados que ajudassem a responder à pergunta principal de nosso estudo, buscou-se: (1) identificar as bases teóricas que sustentam a implantação do PPP como um documento norteador de organização do trabalho pedagógico escolar; (2) refletir sobre a importância do PPP para a comunidade escolar, tornando-a um espaço de diálogo e participação; (3) propor um debate sobre a importância de uma escola reflexiva na construção de seu projeto educativo.

O estudo em foco insere-se numa abordagem qualitativa de investigação com base num estudo de caso realizado na Escola de Ensino Médio em Tempo Integral Governador Cesar Cals de Oliveira Filho, em Quixadá/Ce. Gil (2008), cita o estudo de caso como forma de investigar empiricamente o fenômeno atual dentro do seu contexto de realidade. Para chegar a transcrição dos componentes da pesquisa em foco utilizamos de concepções teóricas, percepções dos sujeitos receptores da política. Os dados forma obtidos por meio do questionário estruturado e o grupo focal, imprescindíveis para definir os resultados de indicadores, dados estatísticos obtidos no PPP da Escola, os relatos orais e escritos de pais e alunos contribuíram para compreender melhor os resultados obtidos.

A LDB (9394/96) aponta o papel da escola e dos professores na elaboração de sua proposta pedagógicas harmonizadas com as políticas nacionais, com as diretrizes dos Estados e municípios, levando em consideração a realidade de cada unidade escolar; voltado para ações democráticas e a transformadoras da realidade local.

Rodrigues (2011) aponta que à trajetória institucional de uma política implementada por órgãos superiores, por meio de um processo descentralizador garante a autonomia das esferas regionais e locais, na execução dessa política.

Baseado nesse pensamento considera-se o PPP como construção coletiva e descentralizadora das ações pedagógica e administrativas da escola, sobretudo da gestão escolar, o PPP pode possibilitar um diagnóstico situacional mostrando que rumo possa tomar na resolução de problemas, diagnosticando os erros e procurando acertar por meio de ações reflexivas que contribuam para crescimento grupal.

Rios (1982) afirma que a escola tem autonomia relativa, Cavagnari (1998) explica que essa autonomia relativa é necessária pois, as escolas precisam de uma assistência técnica e financeira dos órgão competentes mas, esse planejamento burocrático e centralizado precisa dar lugar a um planejamento coletivo e participativo. 
Assim, essa pesquisa propõe um debate sobre o PPP como colaborador no processo de mudança escolar no cumprimento de sua função social, como também propor uma avaliação a respeito do papel para o qual é construído e quais são os empecilhos à sua trajetória no atendimento de sua finalidade educativa.

Alarcão (2004) traz para referência a necessidade da escola trabalhar de forma conjunta, ou seja, que todos sejam integrantes do meio escolar e que alunos e comunidade tomem parte nas decisões a serem tomadas em benefício da melhoria do trabalho a que se propõem a realizar.

Essa ação conjunta defendida por Alarcão (2004), reporta ao que Veiga (1998) aponta que a participação proporciona uma nova organização para a escola que constitui uma ousadia para todos que a compõe, ofertando consciência coletiva na compreensão do papel que cada um exerce nesse processo de construção.

Dessa forma o PPP como fator de mudança, de participação coletiva, traz um novo conceito de Educação, e é um instrumento de organização da unidade escolar, uma referência estrutural para a escola, nos seus diversos setores: pedagógico, administrativo e financeiro (Santos,2009).

Nessa caminhada, o PPP pode possibilitar um movimento de reflexão no interior das escolas, tornando-se um instrumento de organização e gestão escolar, que atenda às demandas sociais atuais, como: o respeito à diversidade, etnicidade, ao sexo, gênero a uma proposta curricular multicultural associada na formação de sujeitos justos, honestos e éticos.

\section{Metodologia}

De acordo com Minayo (1994), compreendemos metodologia como o caminho do pensamento e a prática exercida na abordagem da realidade. E, ainda, a metodologia inclui as concepções teóricas de abordagem; o conjunto de técnicas que possibilitam a construção da realidade. Além disso, a pesquisa científica, sobretudo no viés social, deve abordar o conjunto de expressões humanas constantes em estruturas, processos, sujeitos, significados e representações.

No caminho metodológico, aceitamos a grandiosidade de significados das percepções que os sujeitos receptores têm da política em estudo. Esses significados estão apresentados através de instrumentos e técnicas de pesquisa, que incluem o estudo de caso, questionário estruturado, grupo focal, utilizados com o objetivo de compreender e explicar a dinâmica das relações sociais, que são depositárias de crenças, valores, atitudes e hábitos (Minayo,1994). 
Isso torna-se possível com a abrangência de grupos diversos no processo de investigação, o que permite uma pluralidade de olhares, a partir dos locais ocupados pelos sujeitos da pesquisa.

O estudo de caso enfatiza a "interpretação em contexto" (Lüdke,1986, p.18). Uma forma de compreender com profundidade as percepções dos sujeitos da pesquisa quanto às suas interações, experiências, seus valores e hábitos sociais. O estudo de caso foi realizado na Escola de Ensino Médio em Tempo Integral Governador Cesar Cals de Oliveira Filho, localizada na cidade de Quixadá/Ce, um estabelecimento da rede de ensino oficial, mantido pelo Governo do Estado do Ceará.

Gil (2008) cita que o grupo focal tem o propósito de compreender melhor os problemas e gerar hipóteses, fornece elementos para a construção da coleta de dados. Assim realizamos o grupo focal a fim de compreender a perspectiva interpretativa do PPP sob os pontos de vista dos participantes.

A escolha do questionário estruturado foi para obter informações acerca dos sentimentos, valores, interesses, aspirações, temores e comportamentos apresentados pelos sujeitos relacionados da política em análise. A principal vantagem de apresentar questões abertas é de não forçar o respondente a enquadrar sua percepção em alternativas preestabelecidas (Gil,1999).

Foi necessário ouvir alguns sujeitos envolvidos no processo de elaboração desse documento tão primordial para o trabalho da escola para contemplar à pergunta de partida da pesquisa: O PPP executado nas Escolas da Rede Estadual de Ensino do Ceará está em conexão com a realidade escolar dessas instituições segundo a percepção dos gestores e da comunidade educativa?

Para compor à amostra da pesquisa, escolhemos públicos diferenciados, com o fim de examinar a trajetória e instrumentalização da política em estudo na instituição, ouvimos o núcleo gestor, os professores, alunos e pais.

Finalizando a etapa metodológica da investigação realizamos a revisão bibliográfica sobre os textos e livros que abordam o PPP, utilizando a análise de conteúdo, que foi fundamental na decodificação dos significados emitidos nos discursos dos entrevistados.

No tocante à análise de conteúdo, Bardin (2002, p. 42) diz:

A análise de conteúdo é "um conjunto de técnicas de análise das comunicações visando obter, por procedimentos sistemáticos e objetivos de descrição do conteúdo das mensagens, indicadores (quantitativos ou não) que permitam a inferência de 
conhecimentos relativos as condições de produção/recepção (variáveis inferidas) destas mensagens".

\section{Resultados e Discussão}

Diante dos achados desta incursão, emergem algumas reflexões sobre as respostas no tocante a elaboração do PPP na referida escola, na visão dos professores e núcleo gestor a construção se deu de forma coletiva, entretanto, pais e alunos afirmaram desconhecer esse processo, nesse caso percebeu-se a falta de um alinhamento entre os sujeitos quanto a esse aspecto.

Os resultados dessa pesquisa estão distribuídos em blocos, participação, conhecimento da existência do documento, construção coletiva do PPP, entre outros.

A participação coletiva na implantação do PPP na fala dos sujeitos se deu parcialmente o que constata que a escola vem trabalhando de forma isolada sem a contribuição de alguns segmentos. Quando perguntado aos professores e núcleo gestor, pais e alunos observa-se que alguns desses segmentos não estiveram presentes na construção do PPP.

Sim parcialmente, em reuniões pedagógicas e na construção dos planos de ensino. (Professor 1)

Sim, praticamente construir a espinha dorsal do documento a partir de outros préexistentes. Levei para discussão no coletivo de professores. (Coordenadora Pedagógica)

O PPP foi construído antes de minha chegada na escola, mas, durante a semana pedagógica do ano de 2019, o documento foi aberto e exposto em data show. Eu e os demais professores ajustamos tópicos como a missão da escola, dentre outros tópicos. (Professor 5)

Em partes. Na semana pedagógica da escola, ano sim e ano não (a cada dois anos) o PPP é discutido para analisarmos a necessidade de alterações/ atualizar algumas de suas partes, (Professor 3)

Não participei. (Aluno).

Não participei. (Mãe). 
Apesar dessas lacunas, foi identificado que há uma conexão do processo de implantação do PPP com a realidade escolar, inclusive no que trata o PPP com identidade da escola representando reflexos positivos nas atividades de sua implantação. Essa pergunta foi lançada aos professores e núcleo gestor destacamos algumas respostas:

Sim, acredito nisso, pois o documento reflete a vontade pedagógica da comunidade escolar. (Coordenadora Pedagógica).

O PPP busca traçar ações e metas próprias da escola de acordo com certas concepções pedagógicas e realidades própria da comunidade. Assim a realidade da escola reflete a sua identidade. (Professor 1).

Sim, pois nele está contida a filosofia da escola, sua missão, seus valores. (Professor 3)

Sim. No PPP consta ou deve constar todas as atividades da escola, bem como o perfil da gestão, dos docentes, estrutura física e etc. (Professor 5)

Veiga (1998) aponta que ao elaborar os projetos das escolas, é necessário a intenção de fazer, realizar ações com base naquilo que as escolas dispõem, realizando o que é possível provocando rupturas com o presente para organizar melhor o futuro. Incide numa discussão coletiva sobre as metas que servirão como incentivos em ações educativas embasadas na realidade local direcionadas para ações futuras.

Projeto supõe rupturas com o presente e promessas para o futuro. Um projeto educativo pode ser tomado como promessa frente a determinadas rupturas. As promessas tornam visíveis os campos de ação possível, comprometendo seus atores e autores. (Gadotti, 1994, p. 4).

O PPP é uma ação coletiva de todos os segmentos da escola além. Representa uma direção, um rumo a ser perseguido por todos num compromisso de mudança em busca da qualidade do ensino. Impactando numa construção coletiva. Nos relatos de dois professores, do diretor-geral e da coordenadora pedagógica, torna-se que o processo de construção da escola foi coletivo, porém com adaptações e alterações de tópicos do antigo documento da 
Escola de Ensino Médio Regular, com a Escola em Tempo Integral proposta pela SEDUCCE.

Houve breves encontros para construção do mesmo. Em particular a adequação do regimento ao PPP. (Professor 1)

Na semana pedagógica o PPP é discutido para possíveis alterações em seus tópicos. (Professor 3)

Aconteceu de forma coletiva durante a semana pedagógica e os encontros coletivos. (Professor 2)

Encontro coletivo com toda comunidade escolar- pais, professores, funcionários, alunos e núcleo gestor. (Diretor Geral).

Tomamos como base o documento da Seduc sobre as escolas de tempo integral fizemos adaptação. Trouxemos para o coletivo de professores fazer as devidas alterações ou aprovações. (Coordenadora Pedagógica).

Essa realidade não se configurou quando perguntado aos pais e alunos, os pais relataram por meio da entrevista coletiva que desconheciam essa construção coletiva porque não tiveram a oportunidade de participar desse momento no sentido de contribuir com sugestões para melhoria da escola de seus filhos.

No caso dos alunos, esses relataram não saber como acontece o processo de construção do PPP. Constatamos por meio desses relatos, que a escola construiu seu documento norteador das ações pedagógicas, administrativas e financeiras de forma excludente pois, essa construção se deu forma interna com núcleo gestor e professores sem presença dos pais e dos alunos, conforme mencionado acima.

Conclui-se que não existe na escola, uma mobilização para esse a construção do PPP, os pais se afirmam que a escola não faz esse trabalho, necessitando de um trabalho de sensibilização para que todos tomem conhecimento de fato. O núcleo gestor não propõe momentos na comunidade educativa para que todos possam colaborar desse processo de construção. 
Na elaboração do PPP deve levar em consideração algumas dimensões política, pedagógica e a técnica. Nesse estudo a dimensão pedagógica será discutida, pois no PPP é vista como a intencionalidade da escola, primordial em sua existência. Conforme Veiga (1998),

[...] na dimensão pedagógica reside a possibilidade da efetivação da intencionalidade da escola, que é a formação do cidadão participativo, responsável, compromissado, crítico recriativo. Pedagógico, no sentido de definir as ações educativas e as características necessárias às escolas de cumprirem seus propósitos e sua intencionalidade (p. 13).

Abordar o aspecto pedagógico da escola é falar do cumprimento da sua função social, da socialização dos saberes e na construção de homens críticos, reflexivos, participativos capazes de transformar o ambiente que vivem. Assim “[...] temos que nos alicerçar nos pressupostos de uma teoria pedagógica viável, que parta da prática social e esteja compromissada em solucionar os problemas da educação e do ensino de nossa escola" (Veiga, 1998, p.14).

A dimensão pedagógica está relacionada com às ações em prol da melhoria da qualidade da educação, com as ações educativas da escola, visando atingir seus objetivos no tocante a concepção de homens e mulheres que se quer alcançar. A organização escolar resulta de um trabalho complementar dos eixos financeiro, administrativo e pedagógico esse engloba o currículo escolar, tempo pedagógico, sistema de avaliação, o trabalho do professor no cotidiano da sala de aula, isso reflete numa prática profissional comprometida com a mudança.

Segundo Vasconcellos (2005) a prática deve acontecer de forma coletiva, pois assim favorece um espaço de reflexão crítica, na partilha de dúvidas, inquietações, esperança e descoberta.

Perguntado aos professores e ao núcleo gestor da escola se a dimensão pedagógica é muito significante para o processo de ensino e aprendizagem e com implantação do PPP, houve reflexos (positivos ou negativos) nas atividades pedagógicas desenvolvidas na escola, ficou evidente que não há um alinhamento nas repostas desses sujeitos, as repostas evidenciam que não há um consenso que o PPP vem impactando nas atividades pedagógicas planejadas pelo corpo docente. Vejamos as citações dos sujeitos:

Sim, pois o PPP orienta o cotidiano do trabalho docente e, portanto é um norte a ser seguido para organização do trabalho conjunto dos docentes. (Professor) 
Na verdade, não sei ao certo se o PPP, enquanto documento, é algo que esteja na fala cotidiana dos professores. Talvez esteja na prática, mas não no discurso. (Coordenadora pedagógica).

A legalidade do PPP não garante o seu efetivo alcance na política educacional no âmbito das unidades de ensino, há desafios que dificultam sua operacionalização, inclusive no que se refere à sua implantação, quanto ao acesso desse documento na escola (COSTA, 2019). Constatamos que comunidade educativa precisa tomar conhecimento desse instrumento norteador do trabalho pedagógico perceber que o PPP pode impactar na autonomia pedagógica dessa escola.

Quando indagado aos entrevistados através do questionário estruturado e grupo focal, sobre o nível de conhecimento do PPP da escola os mesmos relataram que:

A escola possui PPP. O documento está disponível no site da escola. Tive acesso pela primeira vez ao PPP na primeira semana pedagógica em que participei. (Professor)

Somos coordenação, então temos que saber desse documento, ele existe, é público, está no site da escola e foi feito pelos professores e demais pessoas da comunidade, revisamos todo ano. (Coordenadora pedagógica).

Vim para uma reunião e eles falaram que queria ajudar os alunos, não sei se era isso. (Mãe)

Nunca ouvi falar. (Aluno)

A comunidade escolar necessita ter conhecimento de que a escola possui um documento que dar norte ao seu trabalho, o PPP, estabelecer aproximação com esse instrumento não deve ocorrer somente na semana pedagógica, pois sua aplicabilidade para melhoria do processo educativo fica comprometida. Como afirma (Costa,2019) o PPP não deve se transformar em um documento de letra-morta, sem vida, como um livro fechado que não se lê e não se conhece o que nele consta. 
Portanto, a escola precisa refletir e discutir as prática pedagógicas aplicadas sob orientação das ações previstas em seu PPP, na possibilidade de uma prática profissional engajada com a mudança. Vasconcellos (2005) afirma que essa reflexão deve acontecer de forma coletiva, pois a prática refletida coletivamente favorece um espaço de expressão crítica, na partilha de dúvidas, inquietações, esperança e descoberta. Dessa forma, com os resultados obtidos na pesquisa, foi possível ampliar o conhecimento sobre o processo de implantação do PPP na escola.

\section{Considerações Finais}

A elaboração e execução do PPP são ações precisas de um prática de gestão democrática, tomar decisões coletivamente e de forma compartilhada favorecem para o surgimento de uma escola que permite a participação e a reflexão, permitindo que o PPP seja de fato um documento norteador do trabalho da escolar.

O Projeto Político Pedagógico numa perspectiva coletiva, tem um conceito importante para o rumo ou o caminho que a escola quer tomar, pois a escola pode até andar sem um planejamento, mas para onde? O PPP colabora para que a escola possa resolver seus problemas, é instrumento de reivindicações na luta por educação transformadora e de qualidade.

$\mathrm{O}$ estudo apresentado neste artigo nos conduziu à conclusão de que a escola precisa fortalecer alguns aspectos e avançar em outros na construção do seu PPP, sobretudo na participação integral de seus segmentos, a não participação dos pais e alunos nessa construção é impedi-los de se sentirem responsáveis por educação compartilhada, compromissada com os resultados que essa escola deseja alcançar.

Portanto, estudos sobre essa temática precisam ser disseminados, despertando outras investigações a respeito de questões aqui levantadas sobre a construção do Projeto político Pedagógico nas escolas públicas.

\section{Referências}

Alarcão, I (2004). Professores reflexivos em uma escola reflexiva. (3. ed.) São Paulo: Cortez.

Brasil (1996). Lei 9.394, de 20 de dezembro de 1996, Lei de Diretrizes e Bases da Educação Nacional. Recuperado de http://www.planalto.gov.br/ccivil_03/Leis/L9394. 
Costa, A. G. de S. (2019). Uma avaliação do processo de implantação do projeto político pedagógico nas escolas da rede estadual de ensino: um estudo de caso em Quixadá-CeDissertação (mestrado) -Universidade Federal do Ceará.

Gadotti, M (1994). O projeto político-pedagógico da escola numa perspectiva de uma educação para cidadania. In Conferência Educação para Todos, Brasília.

Gil, A. C. (2008). Métodos e técnicas de pesquisa social. (6a ed.) São Paulo: Atlas, 2008.

Lücke, M. (1986). Abordagem qualitativa de pesquisa. São Paulo: EPU.

Minayo, C. de S. (1994). (Org). Pesquisa social: Teoria, método e criatividade. Petrópolis: Vozes.

Rodrigues, L. C. (2011, Mar.). Análises de conteúdo e trajetórias institucionais na avaliação de políticas públicas sociais: perspectivas, limites e desafios. CAOS - Revista Eletrônica de Ciências Sociais, UFPB (16), 55-73.

Rios, T (1982). Significado e pressupostos do projeto pedagógico. Série Ideias. São Paulo: FDE.

Santos, A. C. M. (2009). O projeto político-pedagógico como instrumento de mudança organizacional: Limites e possibilidades. Salvador.

Vasconcellos, C. dos S. (2005). Coordenação do trabalho pedagógico: Do projeto políticopedagógico ao cotidiano da sala de aula. São Paulo: Libertad.

Veiga, I. P. A. (1995). Projeto político-pedagógico: Uma construção possível. (24a ed.), São Paulo: Papirus.

Veiga, I. P. A. (1998). Escola: Espaço do projeto político-pedagógico. Campinas: Papirus. Coleção Magistério Formação e Trabalho Pedagógico. 


\section{Porcentagem de contribuição de cada autor no manuscrito}

Adriana Goncalves de Sales Costa - 80\%

Alisandra Cavalcante Fernandes de Almeida - 20\% 